\title{
Simulation Research on Grid Side Inverter of Wind Power Generation System Based on PSCAD
}

\author{
Mengda $\mathrm{Li}^{*}$ \\ ShangHai DianJi University, ShangHai, 201306, China \\ limd@sdju.edu.cn
}

\begin{abstract}
According to the theory of wind power generation combined with specific knowledge of the motor, respectively, including the wind model, the wind shaft drive system physical model, physical model and double fed induction motor (DFIG) mathematical model. On this basis, the corresponding control strategy modeling of the grid side rectifier and the machine side inverter is completed. Finally, the corresponding model of DFIG wind power grid connected system is established in PSCAD/EMTDC simulation software, and the validity of the model and control strategy established in this paper is verified by simulation.
\end{abstract}

Keywords: DFIG; Grid side inverter; PSCAD; Modeling and simulation

\section{Introduction}

At present, the wind power generation is mainly distributed in the micro power grid, because it itself has the advantages of low cost, zero pollution and high efficiency many significant advantages, has become a major solution to the current darling, energy crisis and environmental pollution problems and, in the traditional energy gradually withdraw from the mainstream arena at the same time, the natural resources have gradually become a better alternative [1].

In recent years, wind power from the level of science and technology and the development of the scale of these two terms, have been greatly improved, not only the overall scale is more and more big, the single unit capacity is also growing, from tens of kilowatts to hundreds of kilowatts to the development of the current more popular and more huge MW wind machine. The type of generator has also changed, from the fixed pitch stall type wind turbine to the current mainstream variable pitch constant frequency doubly fed induction generator. Part of the wind turbine doubly fed induction generator connected to the gear box, and then with doubly fed induction generator is connected, and then connected with a group of back-to-back dual PWM regulator, then connect all kinds of protection circuit, finally incorporated into the power grid. In the process of operation, the speed regulation of the wind turbine can be realized by changing the pitch angle, the tip speed ratio and the gear box, so as to complete the maximum wind energy capture [2].

\section{Establishment of Mathematical Model of Wind Power Generation System}

Doubly fed induction wind turbine is mainly composed of high speed low speed shaft, intermediate shaft gear box on the left side and right, therefore, in the capture of wind energy, fan operation, have a certain mechanical energy, not in accordance with the 1:1 mechanical energy transmitted to the doubly fed induction generator, but have a certain ratio, and the ratio will affect the kinetic energy transfer efficiency. The gear ratio in the

Received (November 16, 2017), Review Result (January 10, 2018), Accepted (March 9, 2018) 
transmission system is directly related to the mechanical rotational speed of the left and right ends of the bearing [3]. The relationship between the mechanical speed of the fan impeller and the mechanical speed of the doubly fed machine is $\mathrm{N}_{\omega \mathrm{t}}=\omega_{\mathrm{m}}$. Among them, $\mathrm{N}$ is the gear ratio [4]. The parameters of the low speed side are reduced to the high speed side, and the expression can be obtained as follows:

$$
\frac{d \omega_{m}}{d t}=\frac{T_{t}^{\prime}-T_{e}}{J_{e q}^{\prime}}
$$

Formula: $T_{t}^{\prime}$ represents the mechanical torque of the fan output to the high speed side;

$J_{e q}^{\prime}$ represents the equivalent inertia of the high speed shaft and the sum of the inertia of the low speed shaft to the high speed shaft side.

\subsection{Mathematical Model of Doubly Fed Induction Generator in dq Coordinate System}

The generator can transform the mechanical energy generated by the fan into the electric energy through the motion of the rotor. Because of the ability to transform the physical characteristics of the generator, it has attracted much attention and research. Doubly fed induction generator has the advantages of running speed in a large range, when the low wind speed according to the change of wind speed, maintain the optimal tip speed ratio to get wind, when high speed can store or release energy, improving the system flexibility, make the output more stable [5].

At present, the following three coordinate models are mainly used in the modeling: $a b c$ three phase coordinate model; $\alpha \beta$ two phase stationary coordinate model; $d q$ two phase synchronous rotating coordinate model.

Compared with the previous two models, there is a certain coupling relationship between the three-phase AC component, is not only one kind of variables will affect the results, so the need for decoupling control, in other words, make them only with the single factor, achieve the effect of $d q$ two-phase synchronous rotating coordinate system model is the three-phase AC component of the original by DC component, decoupling control into 2 direction synchronous rotation coordinates so the coordinate system of generator control system design model, relatively easier to control change. Therefore, the mathematical model of the generator will be in the form of $d q$ two phase synchronous rotating coordinate system.

Doubly fed induction generator stator and rotor windings is originally three-phase generator, according to tradition, the use of Park transform [6], can be transformed into the original two-phase three-phase coordinate system, transform the way specific in the model algorithm, the mathematical model expression is as follows:

(1) The flux linkage equation of doubly fed induction generator:

$$
\begin{aligned}
& {\left[\begin{array}{l}
\psi_{s d} \\
\psi_{s q}
\end{array}\right]=\left[\begin{array}{cc}
L_{s} & 0 \\
0 & L_{s}
\end{array}\right]\left[\begin{array}{l}
i_{s d} \\
i_{s q}
\end{array}\right]+\left[\begin{array}{cc}
L_{m} & 0 \\
0 & L_{m}
\end{array}\right]\left[\begin{array}{l}
i_{r d} \\
i_{r q}
\end{array}\right]} \\
& {\left[\begin{array}{l}
\psi_{r d} \\
\psi_{r q}
\end{array}\right]=\left[\begin{array}{cc}
L_{m} & 0 \\
0 & L_{m}
\end{array}\right]\left[\begin{array}{l}
i_{s d} \\
i_{s q}
\end{array}\right]+\left[\begin{array}{cc}
L_{r} & 0 \\
0 & L_{r}
\end{array}\right]\left[\begin{array}{l}
i_{r d} \\
i_{r q}
\end{array}\right]}
\end{aligned}
$$


(2) The voltage equation of doubly fed induction generator:

$$
\begin{aligned}
& {\left[\begin{array}{l}
u_{s d} \\
u_{s q}
\end{array}\right]=\left[\begin{array}{cc}
R_{s} & 0 \\
0 & R_{s}
\end{array}\right]\left[\begin{array}{l}
i_{s d} \\
i_{s q}
\end{array}\right]+\left[\begin{array}{cc}
p & -\omega_{s} \\
\omega_{s} & p
\end{array}\right]\left[\begin{array}{l}
\psi_{s d} \\
\omega_{s q}
\end{array}\right]} \\
& {\left[\begin{array}{l}
u_{r d} \\
u_{r q}
\end{array}\right]=\left[\begin{array}{cc}
R_{r} & 0 \\
0 & R_{r}
\end{array}\right]\left[\begin{array}{l}
i_{r d} \\
i_{r q}
\end{array}\right]+\left[\begin{array}{cc}
p & -s \omega_{s} \\
\omega_{s} & p
\end{array}\right]\left[\begin{array}{l}
\psi_{r d} \\
\psi_{r q}
\end{array}\right]}
\end{aligned}
$$

The (2) and (3) two groups of equations are brought into (4) and (5) two groups of equations respectively. After a certain simplification, the voltage equations of two new doubly fed induction generators are obtained, and the following two groups of equations are presented:

$$
\begin{aligned}
& {\left[\begin{array}{l}
u_{s d} \\
u_{s q}
\end{array}\right]=\left[\begin{array}{cc}
R_{s}+p L_{s} & -\omega_{s} L_{s} \\
\omega_{s} L_{s} & R_{s}+p L_{s}
\end{array}\right]\left[\begin{array}{l}
i_{s d} \\
i_{s q}
\end{array}\right]+\left[\begin{array}{cc}
p L_{m} & -\omega_{s} L_{m} \\
\omega_{s} L_{m} & p L_{m}
\end{array}\right]\left[\begin{array}{l}
i_{r d} \\
i_{r q}
\end{array}\right]} \\
& {\left[\begin{array}{l}
u_{r d} \\
u_{r q}
\end{array}\right]=\left[\begin{array}{cc}
p L_{m} & -s \omega_{s} L_{m} \\
s \omega_{s} L_{m} & p L_{m}
\end{array}\right]\left[\begin{array}{l}
i_{s d} \\
i_{s q}
\end{array}\right]+\left[\begin{array}{cc}
R_{r}+p L_{r} & -s \omega_{s} L_{r} \\
s \omega_{s} L_{r} & R_{r}+p L_{r}
\end{array}\right]\left[\begin{array}{l}
i_{r d} \\
i_{r q}
\end{array}\right]}
\end{aligned}
$$

(3) The electromagnetic torque equation of doubly fed induction generator is as follows:

$$
T_{e}=\frac{3}{2} n_{p}\left[\psi_{s d} i_{s q}-\psi_{s q} i_{s d}\right]
$$

\subsection{Design of Inverter Control System for Wind Power Generation}

At present, the grid connected converter of wind power generation system adopts more double PWM back to back structure, that is to say, the machine side rectifier and the grid side inverter are arranged in a backpack type.

The so-called decoupling control system, is to use a specific algorithm structure, find the appropriate control law to remove a specific contact two originally associated with the control circuit in the system [6], so that each input control only a corresponding output, each output only by a control role. It is popular to the correspondence function can be expressed as $y=f(x)$.

\subsection{Control Strategy of Grid Side Inverter}

The control block diagram of the grid side inverter is shown in Figure 1. It is a typical voltage outer loop, current inner loop and double loop control system. From the diagram, it is known that the vector needed to control is the current: 


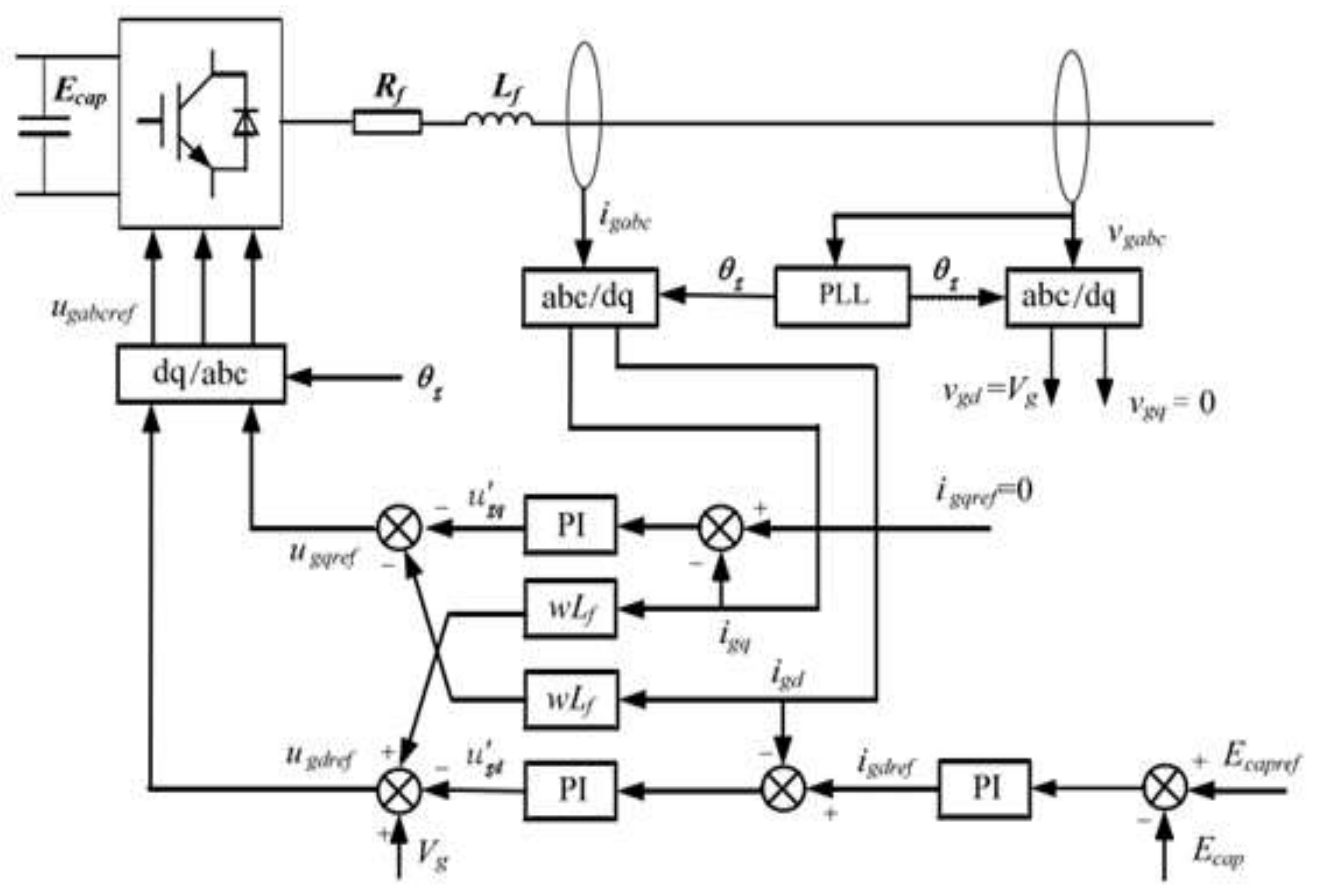

Figure 1. Block Diagram of Control Strategy for Grid Side Inverter

(1) The coordinate transformation grid side current voltage: by measuring the actual grid side voltage and current values can be obtained: $v_{g a b c}$ and $i_{g a b c}$, were transformed into dq two-phase synchronous rotating coordinate system transform abc three-phase coordinate system on the grid side voltage and current measurement, with abc three-phase coordinate transformation to transform the dq two-phase rotating synchronous coordinate system. Its significance lies in the transformation between different coordinate system to describe the model more convenient, the so-called decoupling control, so that you can get in dq two-phase rotating coordinate system of the synchronous voltage and current components $v_{g d}, v_{g q}, i_{g d}$ and $i_{g q}$.

(2) Voltage loop: DC voltage $E_{\text {cap }}$ and DC side voltage $E_{\text {capref }}$ compares their difference through the PI regulator to control and adjust the output of the $i_{g d r e f}$, that is the input of the next comparator.

(3) Current loop: current inverter through dq two-phase synchronous rotating coordinates are $i_{g d}, i_{g d r e f}$ and $i_{g d}$ are compared, then the difference by PI regulator, the modulation signal $u_{\text {gdref }}$ of $\mathrm{d}$ axis voltage can be obtained. Similarly, the q axis voltage $u_{\text {gqref }}$ can be obtained. Then the three-phase voltage modulated wave signal can be obtained by inverting the inverter.

\section{Model Establishment and Parameter Setting of DFIG Example Structure}

As the DFIG wind power generation in this paper uses the gradual wind modeling and simulation, so the model diagram is as follows: 


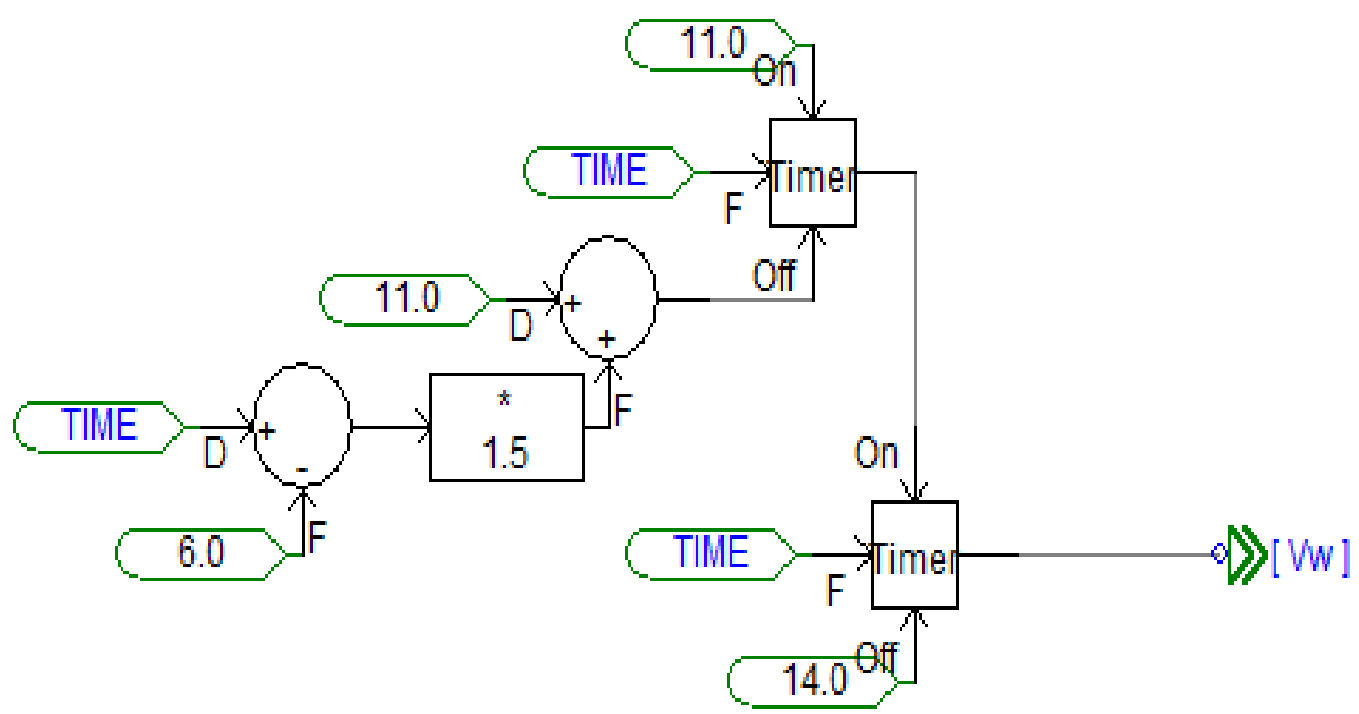

Figure 2. Gradual Wind Model of DFIG

The simulation in the doubly fed induction generator in the example, the wind speed may exceed the rated wind speed sensor, according to the relationship between the pitch angle and wind speed and the structure diagram of pitch control system can know, in a doubly fed induction generator simulation example, when not to exceed the rated wind speed, constant pitch angle is 0; when exceeding the rated wind speed and pitch angle need to make corresponding changes. Therefore, it is necessary to model and simulate the pitch angle of doubly fed induction generator, and the specific model is shown in the following picture:

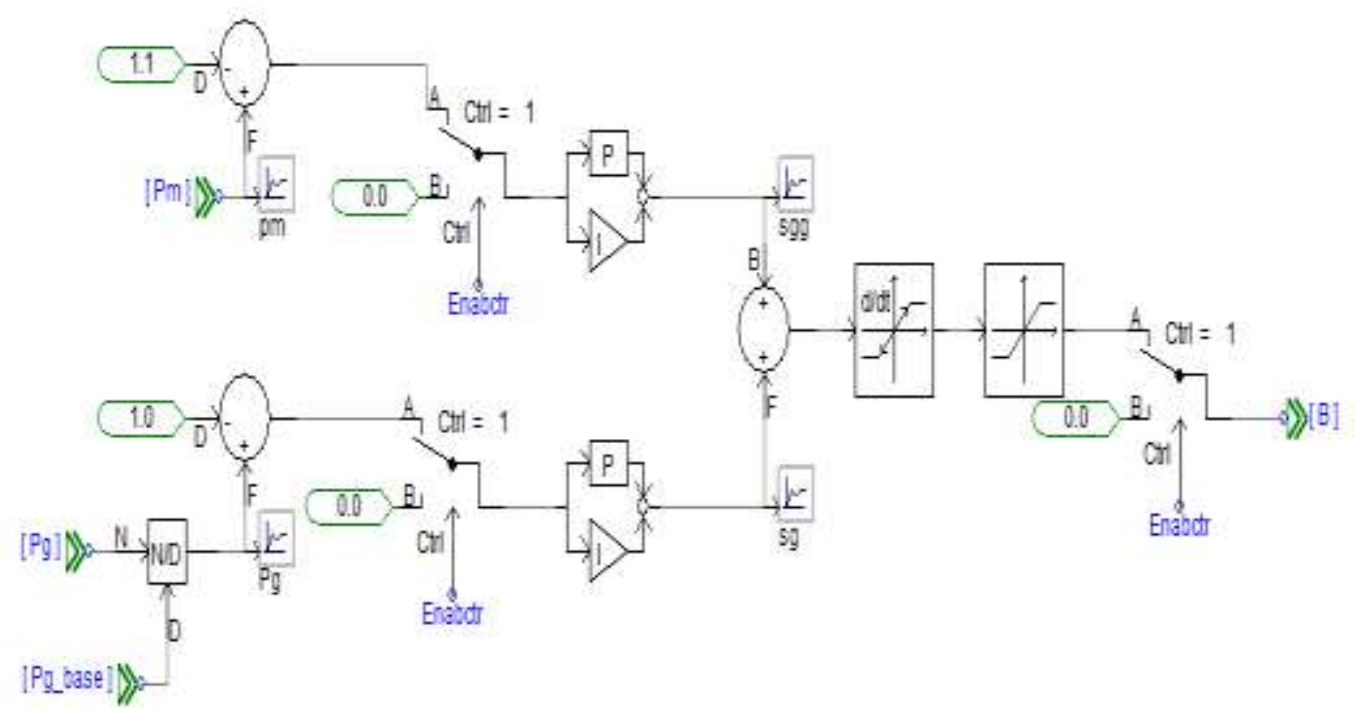

Figure 3. Pitch Angle Control System Model

The inverter consists of 6 IGBT, a full controlled bridge rectifier circuit and a fully controlled bridge inverter circuit. The specific model diagram is shown in the following figure: 




Figure 4. Inverter Model

\section{Simulation Results Analysis of Wind Power Generation System}

\subsection{Simulation of Gradient wind in DFIG}

Considering the complexity of the algorithm and simulation, here still used a single type of wind, the wind gradient, but the comprehensive wind: at the time of $0-6 \mathrm{~s}$, the wind speed $\mathrm{Vw}$ remained unchanged at $11 \mathrm{~m} / \mathrm{s}$; at $6-8 \mathrm{~s}$, the wind speed has a gradually rising trend, gradually increased to $14 \mathrm{~m} / \mathrm{s}$, when more than $6.4 \mathrm{~s}$ the rated wind speed $\mathrm{Vn}$; in $8-20 \mathrm{~s}$, the wind speed remains unchanged at $14 \mathrm{~m} / \mathrm{s}$, the wind speed model simulation results are as follows:

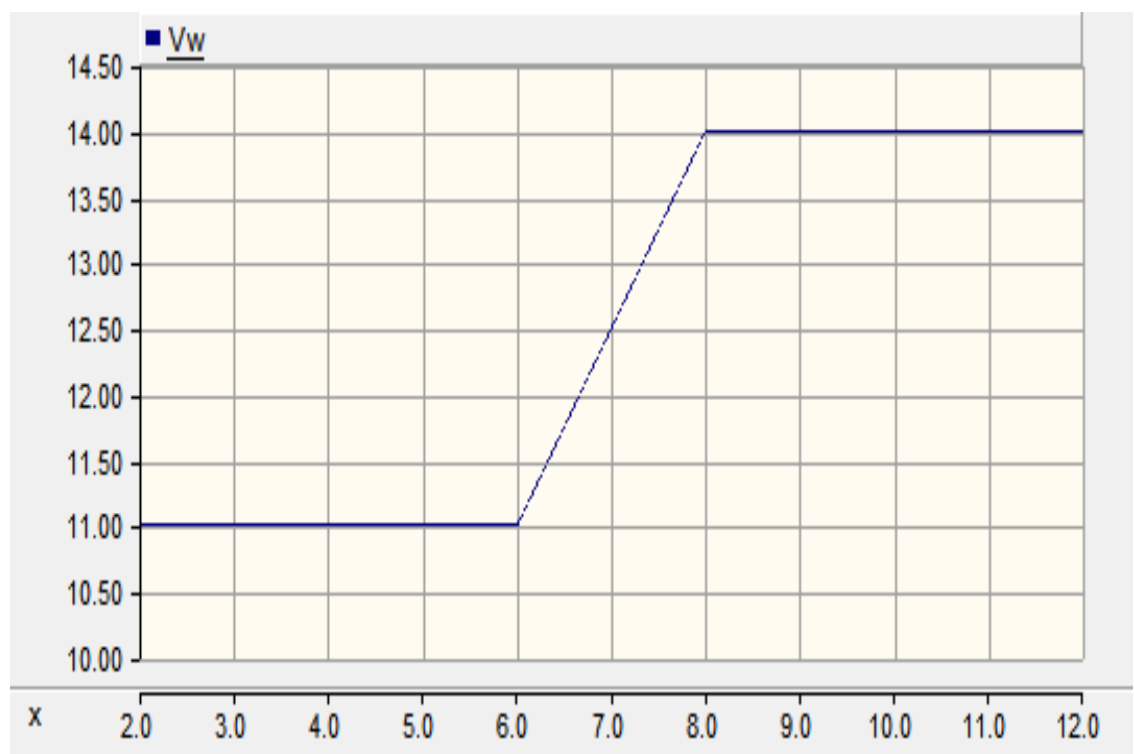

Figure 5. Simulation Results of Gradual Wind in DFIG

Since the gradient wind has a gradual rise process, there are two stages: less than one section of the rated wind speed and more than the rated wind speed. 


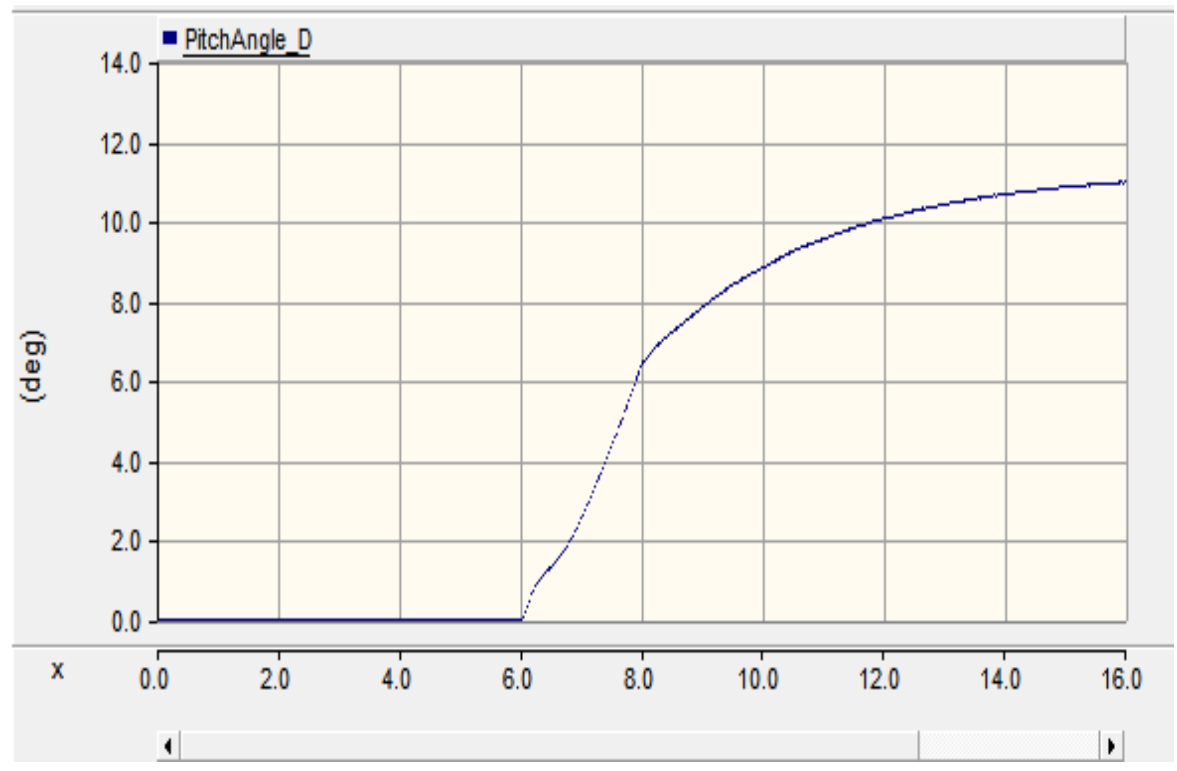

Figure 6. Simulation Results of Pitch Angle System

As can be seen from Figure 6: at the time of 0-6s, the wind speed has been lower than the rated wind speed, according to the system diagram, pitch control can be obtained, the pitch angle beta is 0 degrees, is indeed consistent with theory; when the wind speed exceeds the rated wind speed and pitch angle control system is transformed into a closed state, the system began operations in a certain to adjust the pitch angle, due to the gradual increase in wind speed, pitch angle and wind speed is proportional to the pitch angle increase gradually, can be shown in Figure 6 the pitch waveform, showing an increasing function.

From Figure 7 and 8 we can see that when the pitch angle increases, which corresponds to the optimum tip speed ratio decreases, the horizontal axis gradually tends to 0; the maximum wind energy conversion coefficient of the corresponding decreases, vertical axis gradually tends to 0 , in line with its characteristic curve.

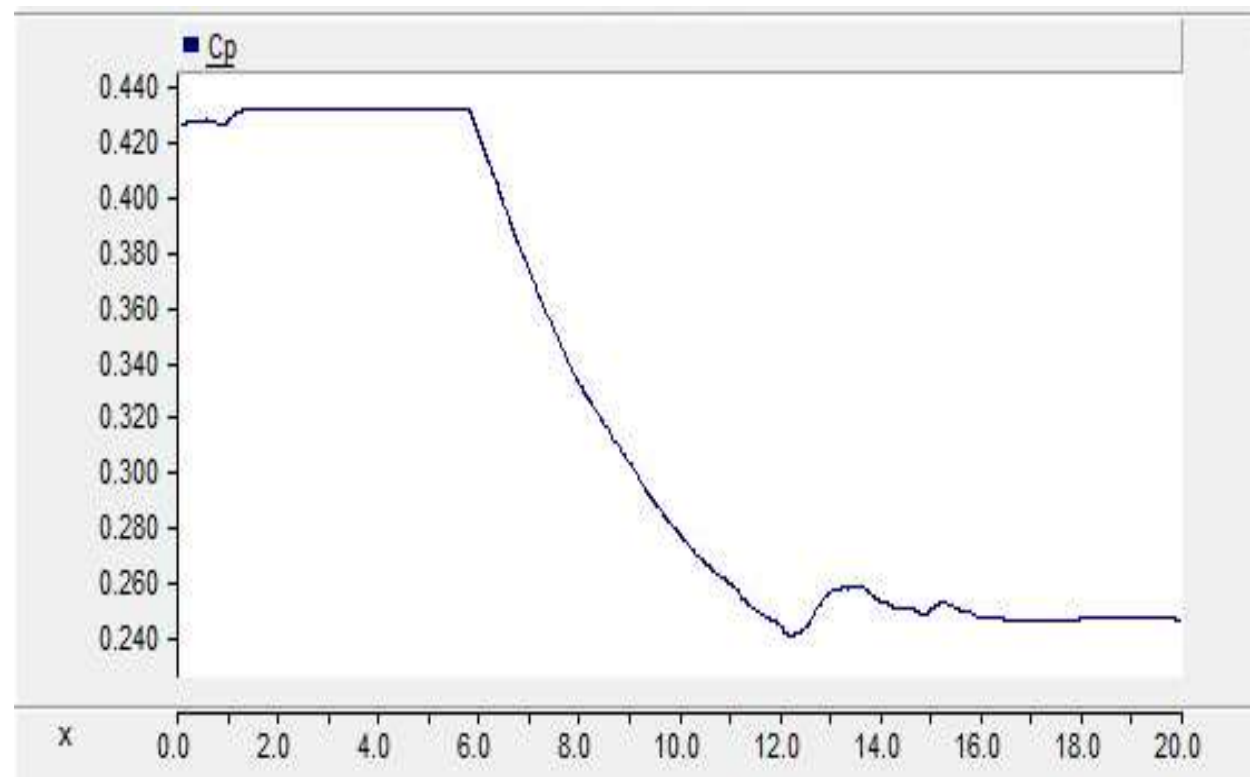

Figure 7. Variation Curve of Tip Velocity Ratio $\lambda$ 


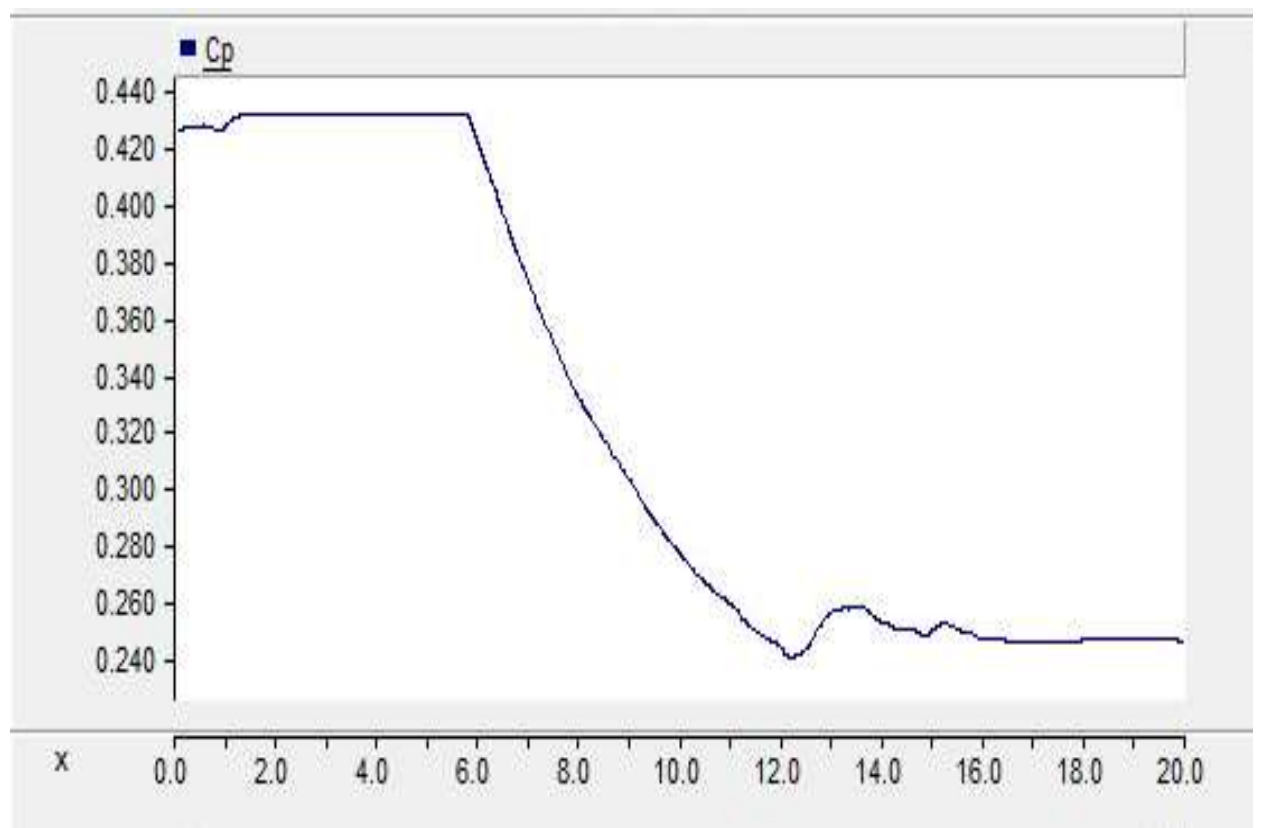

Figure 8. Variation Chart of Wind Energy Conversion Coefficient Cp

You can see from Figure 9, when the rated wind speed, wind power output has been maintained at the rated power within 6 seconds; from the wind speed exceeds rated time, excess fan operation, so that the output power increases gradually, this time, the pitch control system has already started, the output power of wind turbine should be reduced, but because the wind is still increasing and the role of mechanical inertia of the motor, the rotor speed and can't be timely correction to the rated value, LED fan still has a short period of time is running over, of course this is inevitable, but also has some damage, after the end of inertia, the output power gradually back to the rated power, so it can be seen from Figure 9, in 8 seconds after the curve began to decline, then gradually stabilized, protection at rated power.

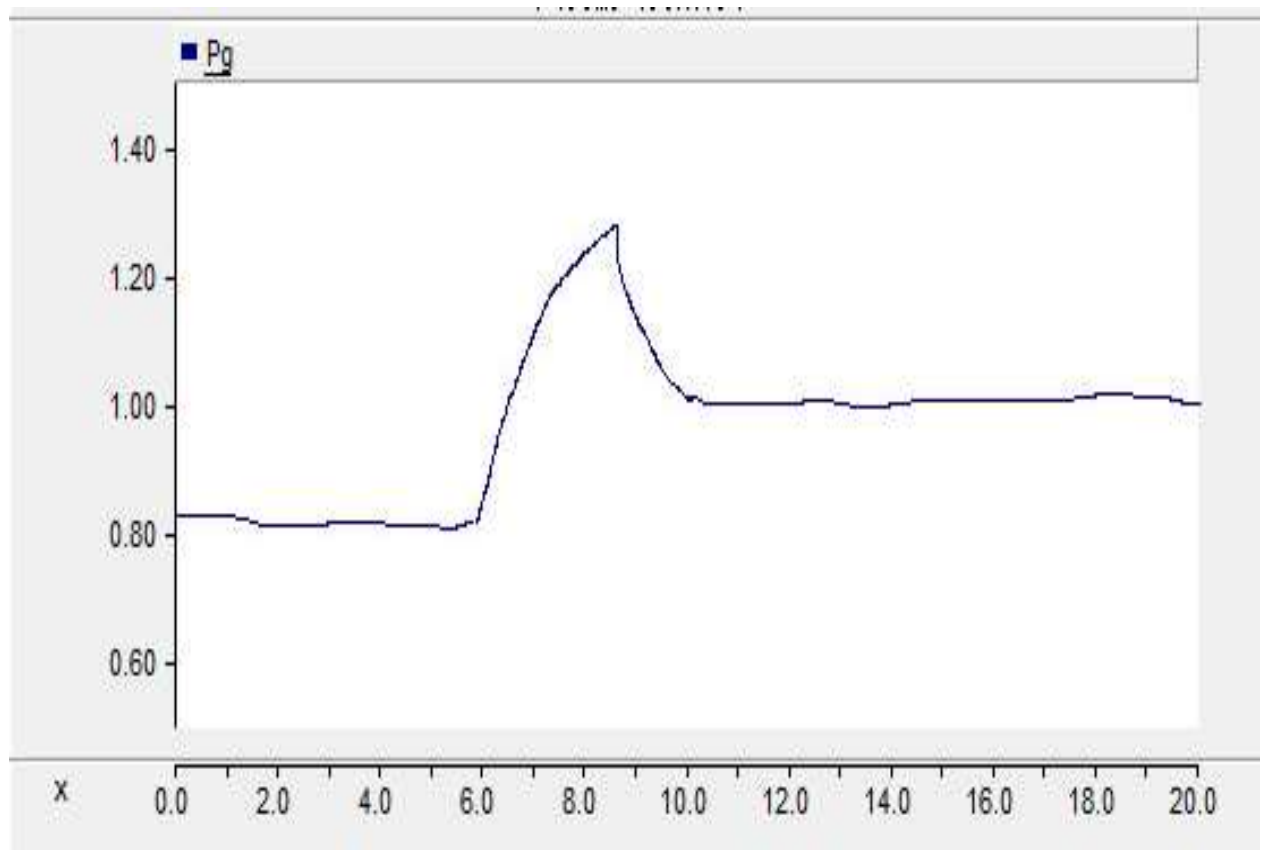

Figure 9. Variation Curve of Fan Output Power 
In summary, the control strategy adopted in this paper can make the DFIG unit operate within the rated conditions and can be adjusted timely under excess conditions.

\subsection{Simulation Results and Analysis of Network Side Control System}

According to the Figure 10 can be seen in the process of matrix style changes in the current $i_{g d}$ network side can track the $\mathrm{d}$ axis d axis current command value $i_{g d r e f}$.

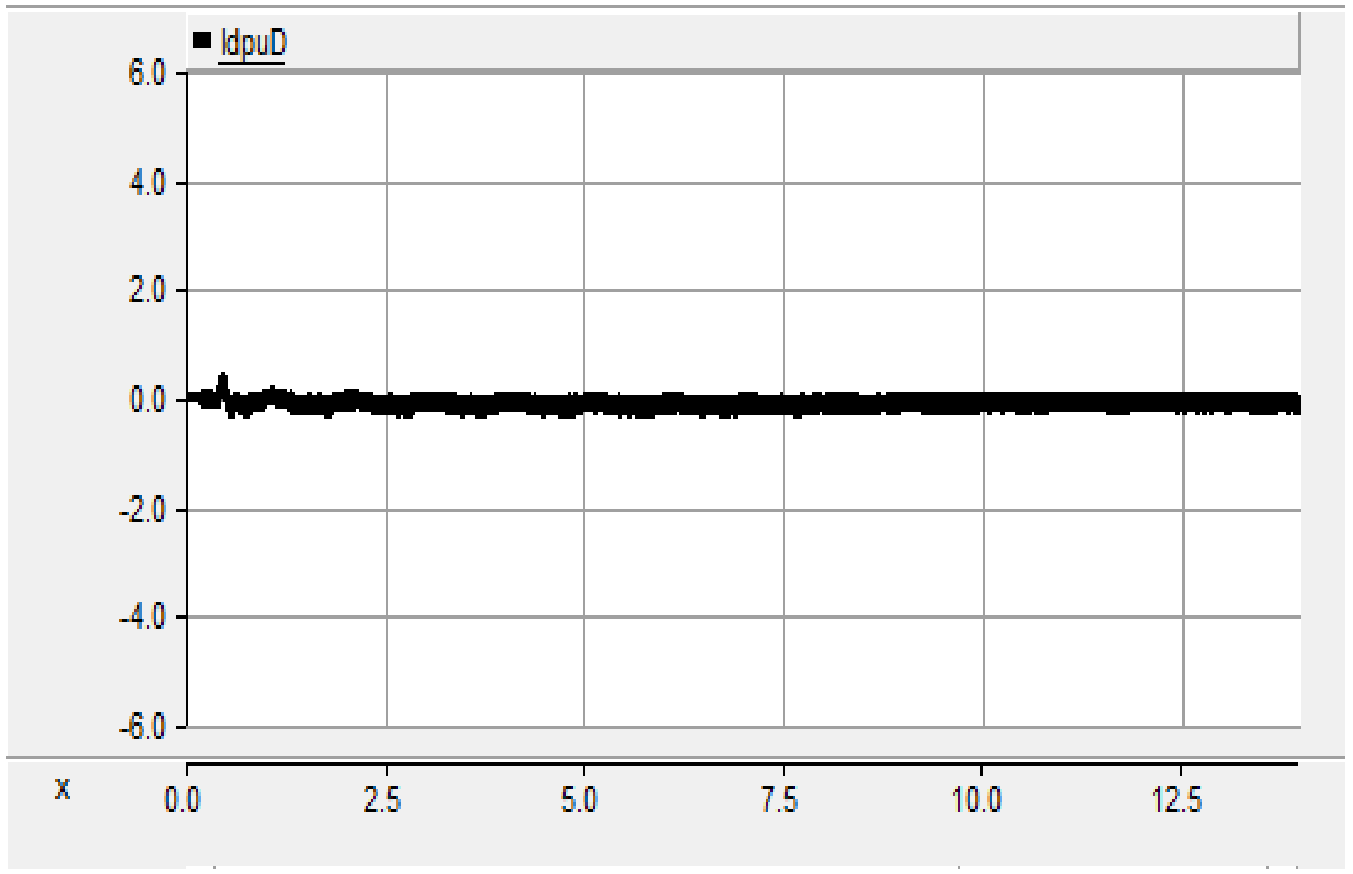

Figure 10. Tracking Waveform of d Axis Current igd on Grid Side

As can be seen from Figure 11, in the process of matrix style change, network side inverter basically can maintain output voltage stability, not affected by wind speed.

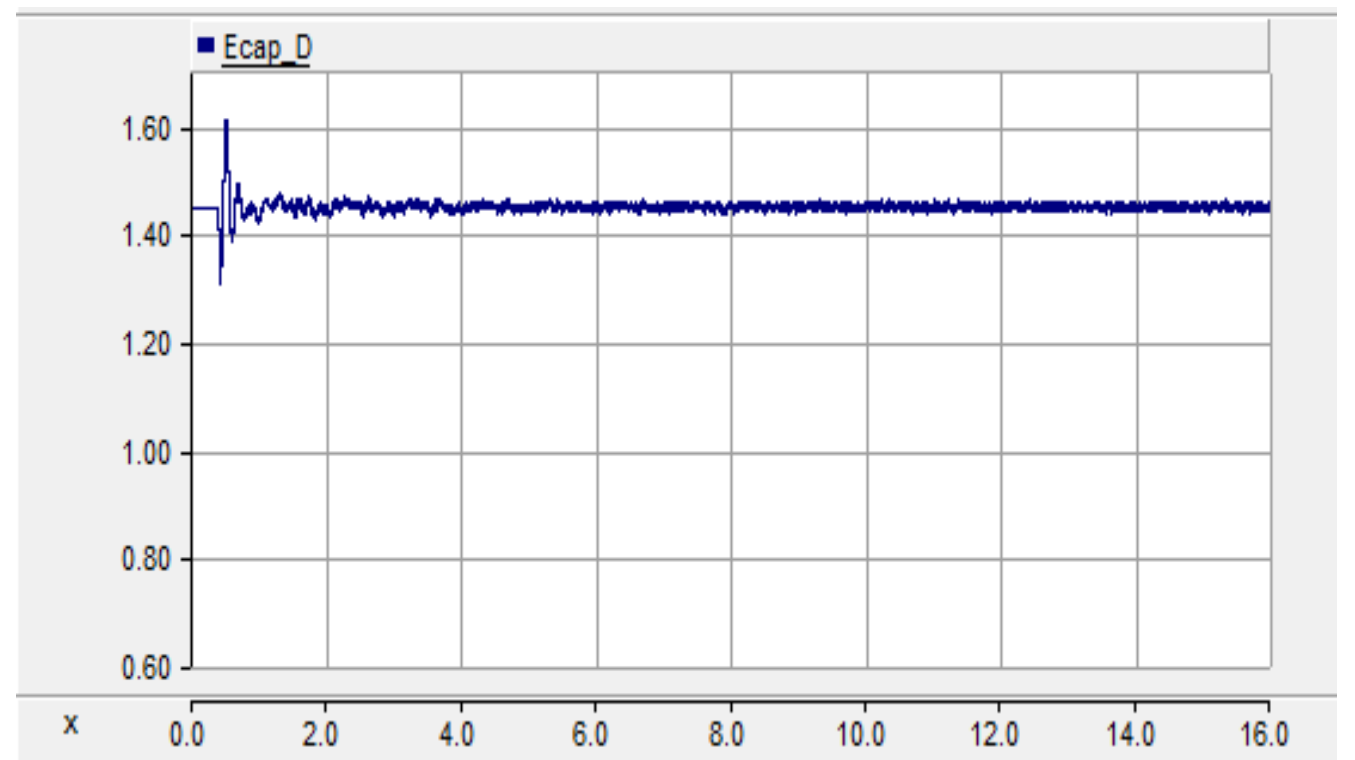

Figure 11. Waveform of DC Side Voltage Ecap 
As can be seen from Figure 11, grid side inverter reactive power constant is 0 , not with the wind speed change and produce change, according to the formula $\cos \alpha=\mathrm{P} / \mathrm{S}$, the power factor can be introduced: when the reactive power $\mathrm{Q}$ is 0 , the power factor is equal to 1 , to achieve unit factor control, so the network side control when using the dq axis current control, DC voltage and grid side inverter power factor stability successfully.

\section{Conclusion}

The rise of wind power generation system has solved some energy problems and environmental pollution problems for the world. However, due to the immaturity of the current technology, the wind power generation technology is not popular enough and not stable, low efficiency is also the current mainstream issues. Based on doubly fed induction generator (DFIG) wind power generation system structure composed of the use of gradient wind simulation, wind speed for the rated wind speed exceeds rated wind speed and less than two, therefore, the simulation results of the map will have a change process, at the same time, start the pitch control system will have a certain the influence of waveform of the final, except for short time wind speed exceeds rated wind speed, the other part of the basic waveform can guarantee the tracking in the command value acceptable error range, the control strategy is verified.

\section{Appendix}

Schedule: List of main parameters

Table 1. Main Parameters of Wind Turbine in DFIG Grid Connected System

\begin{tabular}{|c|c|c|}
\hline Parameter name & unit & value \\
\hline Rated mechanical power $P_{t n}$ & MW & 2 \\
\hline Rated mechanical speed $\omega_{t n}$ & $\mathrm{rad} / \mathrm{s}$ & 1.154 \\
\hline Rated wind speed $V_{n}$ & $\mathrm{~m} / \mathrm{s}$ & 11.583 \\
\hline Impeller radius $R$ & $\mathrm{~m}$ & 40 \\
\hline Air density $\rho$ & $\mathrm{kg} / \mathrm{m} 3$ & 1.169 \\
\hline Gear ratio $N$ & -- & 83 \\
\hline
\end{tabular}

Table 2. Main Parameters of Doubly Fed Induction Generator in DFIG Grid Connected System

\begin{tabular}{|c|c|c|}
\hline Parameter name & unit & value \\
\hline Rated power $S_{n}$ & MVA & 2 \\
\hline Rated line voltage $U_{n}$ & KV & 0.69 \\
\hline Rated synchronous angular frequency $\omega_{s}$ & rad/s & 376.99 \\
\hline Stator winding resistance $R_{s}$ & PU & 0.55 \\
\hline Rotor winding resistance $R_{r}$ & PU & 0.55 \\
\hline Stator winding inductance $L_{s}$ & PU & 0.1 \\
\hline Rotor winding inductance $L_{r}$ & PU & 0.11 \\
\hline Excitation inductance of motor $L_{m}$ & PU & 4.5 \\
\hline
\end{tabular}


Table 3. Network Side Parameters of DFIG Grid Connected System

\begin{tabular}{|c|c|c|}
\hline Parameter name & unit & value \\
\hline Voltage level of power grid & KV & 20 \\
\hline Transformer T1 ratio K1 & -- & $0.69 / 20$ \\
\hline Transformer T2 ratioK2 & -- & $0.69 / 20$ \\
\hline Filter inductance $L_{f}$ & $\mathrm{H}$ & 0.0012 \\
\hline Filter resistor $R_{f}$ & $\Omega$ & 0.001 \\
\hline Line inductance $L_{l}$ & $\mathrm{H}$ & 0.04 \\
\hline Line resistance $R_{l}$ & $\Omega$ & 2.4 \\
\hline DC regulated capacitor $C$ & $\mu \mathrm{F}$ & 6800 \\
\hline
\end{tabular}

\section{References}

[1] L. Jinyong, L. Zhanying, L. Zehan and X. Hai, "Distributed power generation technology and its impact on power system research", Nanfang power grid technology, vol. 5, no. 4, (2011), pp. 46-50.

[2] W. Chengshan and L. Peng, "Distributed generation, microgrid and smart distribution network development and challenges", Power system automation, vol. 35, no. 12, (2010), pp. 75-81.

[3] T. Xiaofeng, "Control strategy of distributed complementary energy microgrid system", Master's degree thesis of HeFei University of Technology, (2010).

[4] D. Tongyu, "Direct drive wind turbine modeling and grid connected simulation analysis", Master's degree thesis of Taiyuan University of Technology, (2011).

[5] L. Binbin, "Research on voltage stability of large scale wind power grid connected system", Master's degree thesis of HeFei University of Technology, (2011).

[6] W. Haitao, "Research on converter control system of direct drive wind power generation system", Master's degree thesis of North China Electric Power University, (2011).

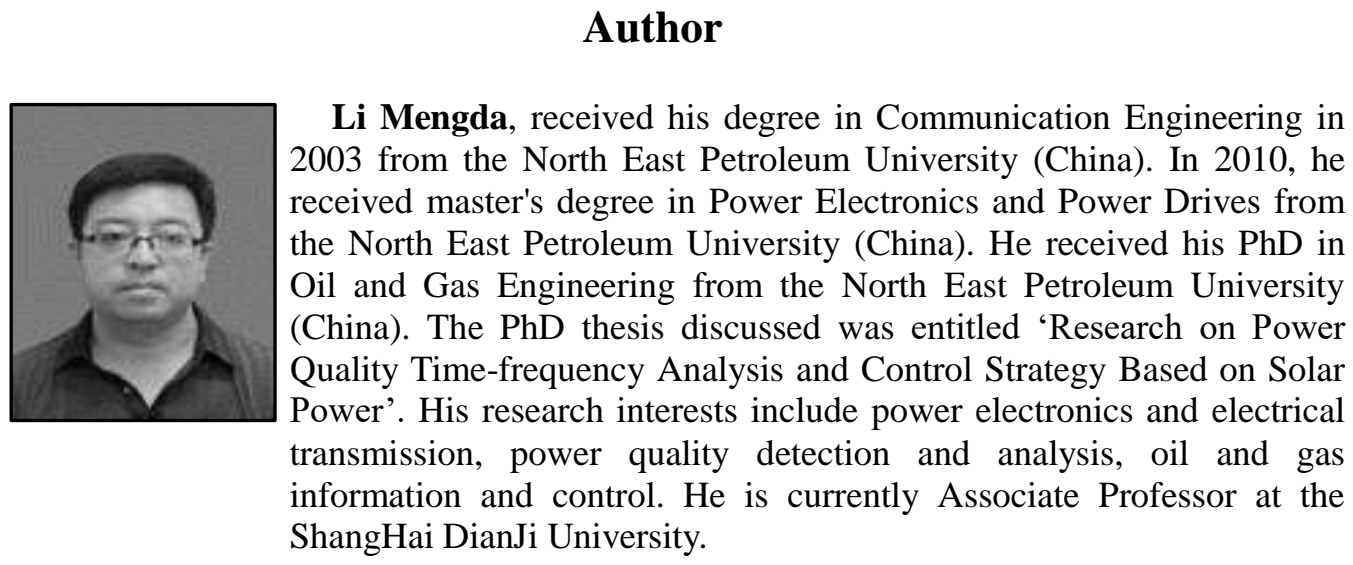


International Journal of Grid and Distributed Computing

Vol. 11, No. 4 (2018) 